\title{
Family history of cancer in Japanese gastric cancer patients
}

\author{
Kentaro Kawasaki, Kiyonori Kanemitsu, Takashi Yasuda, Takashi Kamigaki, Daisuke Kuroda, \\ and YoshiKazu Kuroda \\ Division of Gastroenterological Surgery, Department of Clinical Molecular Medicine, Kobe University, Graduate School of Medicine, \\ 7-5-2 Kusunoki-cho, Chuo-ku, Kobe 650-0017, Japan
}

\begin{abstract}
The aim of this study was to evaluate the family history of cancer in Japanese gastric cancer patients and to investigate the clinicopathological features of gastric cancer patients with and without a family history of cancer. Four hundred and forty gastric cancer patients were enrolled in this study. The family history (first- and second-degree relatives) was investigated. The 440 patients were divided into three groups: (1) patients with a family history of gastric cancer; (2) patients with a family history of other cancers; and (3) patients without a family history of cancer. Two hundred and four patients (46.4\%) reported a family history of cancer. Gastric cancer was the most frequent, with 98 patients having a total of 123 reports of gastric cancer in the family; colorectal cancer was the second most frequent and lung cancer was the third most frequent. The average ages of the group with a family history of gastric cancer and the group with a family history of other cancers were significantly lower than that of the patients without a family history of cancer. Other clinicopathological factors examined showed no significant difference between the groups. Japanese gastric cancer showed aggregation within second-degree relatives. The average age of the patients in the group with a family history of gastric cancer was the only significant factor that differed between gastric cancer patients with and without a family history of cancer.
\end{abstract}

Key words Gastric cancer · Family history · Japan . Aggregation

\section{Introduction}

Gastric cancer is one of the most common cancers in Japan; approximately 81.8 people per 100000 developed gastric cancer in 2000, and 40.1 people per 100000 die of this disease [1].

Offprint requests to: $\mathrm{K}$. Kawasaki

Received: December 18, 2006 / Accepted: May 7, 2007
In patients with gastric cancer, the most frequently reported family history of cancer is that of gastric cancer [2-4]. Aggregation of gastric cancer has been reported previously. The odds ratio (OR) for the development of gastric cancer in an individual with a family history of gastric cancer has been reported to be 1.6-2.6 [4-7]. Many factors, such as genetic, epigenetic and environment factors, seem to contribute to this correlation [8].

Only a few reports have described a detailed family history of cancer in the gastric cancer patient [2]. In this study, we examined the family history of cancer in firstand second-degree relatives (within second-degree relatives) of gastric cancer patients. In addition, we investigated clinicopathological factors to determine the characteristic features of the familial clustering of gastric cancer.

\section{Patients and methods}

Four hundred and ninety-four patients with primary gastric cancer, who were diagnosed and underwent resection at the Department of Gastroenterological Surgery, Kobe University, between 1997 and 2004, were enrolled in this study. The family histories of the patients were taken by medical doctors on admission. Of these patients, a clear family history was obtained for 440 of them. The 440 patients were divided into three groups: (1) patients with a family history of gastric cancer (gastric-cancer group); (2) patients with a family history of other cancers (other-cancers group); and (3) patients without a family history of cancer (none). Positivity for a family history of cancer was defined as a history of cancer within second-degree relatives.

The Japanese classification of gastric carcinoma (second English edition; 1998) was used to describe and classify all variables throughout this study [9].

Discrete variables were analyzed by the $\chi^{2}$ test, factorial analysis of variance (ANOVA), and logistic regres- 
sion. Statistical significance was indicated at $P<0.05$. All statistical computations were carried out using StatView 5.0 software (SAS Institute, Cary, NC, USA).

\section{Results}

The overall ranking of a family history of cancer within second-degree relatives in the gastric cancer patients is shown in Table 1. Two hundred and four patients were classified as positive. A family history of gastric cancer was the most frequent, with 98 patients having a total of 123 reports of gastric cancer in the family; colorectal cancer was the second most frequent and lung cancer was the third most frequent.

The clinicopathological features of each group are shown in Table 2. The average age of the gastric-cancer group and the other-cancers group was significantly lower than that of the patients without a family history of cancer ("none" in Table 2). There were no significant differences between the groups in other clinicopathological factors.

The results of the logistic regression analysis in relation to a family history of gastric cancer are shown in Table 3. None of the factors showed a significant relationship with the family history of cancer.

\section{Discussion}

In Japan, as reported for 2000, the incidence of gastric cancer was approximately 81.8 per 100000 population, while that of colorectal cancer was 72.6 and that of lung cancer was 53.5 [1]. Therefore, the incidence of gastric cancer is approximately 1.13 -fold higher than that of colorectal cancer and 1.53-fold higher than that of lung

Table 1. Family history of cancer in gastric cancer patients

\begin{tabular}{lcc}
\hline Family history & \multicolumn{2}{c}{ Number of patients (\%) } \\
\hline $\begin{array}{l}\text { Negative } \\
\text { Positive }\end{array}$ & & $236(53.6)$ \\
& & $204(46.4)$ \\
\hline & Number of & Number of \\
Organ & $98(36.6)$ & $123(40.9)$ \\
\hline Stomach & $43(16.0)$ & $48(16.0)$ \\
Colorectum & $29(10.8)$ & $31(10.3)$ \\
Lung & $17(6.3)$ & $17(5.7)$ \\
Uterus & $16(6.0)$ & $17(5.7)$ \\
Liver & $13(4.9)$ & $13(4.3)$ \\
Breast & $13(4.9)$ & $13(4.3)$ \\
Esophagus & $12(4.5)$ & $12(4.0)$ \\
Pancreas & $8(3.0)$ & $8(2.7)$ \\
Larynx-pharynx & $19(7.1)$ & $19(6.3)$ \\
Others & $268(100.0)$ & $301(100.0)$ \\
Total &
\end{tabular}

cancer. In the present study, the ratio of the gastric cancer was $40.8 \%$, which was greater than twice that of colorectal cancer and lung cancer. Consistent with previous reports [2-7], familial clustering of gastric cancer was observed in the present study. Recently, Bernini et al. [2] reported on the family history of cancer in gastric cancer patients in Italy. In their report, gastric cancer was the most common family history of cancer in the patients with gastric cancer, and approximately $21.9 \%$ of the gastric cancer patients had a family history of gastric cancer; colorectal cancer was the second most frequent, followed by breast cancer. In their report, $46.8 \%$ of all patients had a family history of cancer, and $36.7 \%$ of these patients had a family history of gastric cancer. Therefore, the incidence of gastric cancer is similar in Italy and Japan.

In our study, all the patients were divided into three groups to clarify the features of the familial clustering of gastric cancer, and we found that age was the only significant factor that differed between the patients with a history of gastric cancer and those without such a history. In contrast, Bernini et al. [2] reported that intestinal type was a significant factor in their gastric cancer group, although there are a few differences between their study and ours. However, the characteristics of gastric cancer patients with a family history of gastric cancer are controversial. Inoue et al. [10] reported that gastric cancer was found more frequently in the lower and middle part of the stomach in their gastric cancer patients with a family history of gastric cancer. Eto [10] reported that the histology, age, and location were significant familial clustering factors. The clinicopathological factors in gastric cancer patients with a family history of gastric cancer are controversial, because many factors may be related to the development of cancer in this group.

In conclusion, in the present study in gastric cancer patients, gastric cancer was the most frequent family history of cancer. Obtaining a family history of cancer in the gastric cancer patient is important, and gastric cancer patients who are young and have a family history of gastric cancer should be carefully followed.

\section{References}

1. National Cancer Center Japan. Cancer information. http:// ganjoho.ncc.go.jp/pro/statistics/index.html.

2. Bernini M, Barbi S, Roviello F, Scarpa A, Moore P, Pedrazzani $\mathrm{C}$, et al. Family history of gastric cancer: a correlation between epidemiologic findings and clinical data. Gastric Cancer 2006;9: 9-13.

3. Ogawa H, Kato I, Tominaga S. Family history of cancer among cancer patients. Jpn J Cancer Res 1985;76:113-8.

4. Bakir T, Can G, Siviloglu C, Erkul S. Gastric cancer and other organ cancer history in the parents of patients with gastric cancer. Eur J Cancer Prev 2003;12:183-9. 
Table 2. Comparison of groups with different family histories of cancer

\begin{tabular}{|c|c|c|c|c|}
\hline Family history & $\begin{array}{l}\text { Gastric } \\
\text { cancer }\end{array}$ & $\begin{array}{c}\text { Other } \\
\text { cancers }\end{array}$ & None & \\
\hline Number of patients & 98 & 106 & 236 & 440 \\
\hline Male/Female & $64 / 34$ & $73 / 33$ & $167 / 69$ & NS \\
\hline Average age (years) & 64.4 & 64.5 & 67.7 & $P<0.05$ \\
\hline \multicolumn{5}{|l|}{ Past history of cancer } \\
\hline- & 76 & 83 & 176 & \multirow[t]{2}{*}{ NS } \\
\hline+ & 22 & 23 & 60 & \\
\hline \multicolumn{5}{|c|}{ Number of cancers in family } \\
\hline 0 & 0 & 0 & 236 & \multirow[t]{6}{*}{ NS } \\
\hline 1 & 54 & 78 & 0 & \\
\hline 2 & 29 & 26 & 0 & \\
\hline 3 & 8 & 1 & 0 & \\
\hline 4 or more? & 7 & 1 & 0 & \\
\hline Average & 1.67 & 1.28 & 0 & \\
\hline \multicolumn{5}{|l|}{ Region } \\
\hline $\mathrm{U}$ & 24 & 26 & 64 & \multirow[t]{3}{*}{ NS } \\
\hline M & 41 & 41 & 96 & \\
\hline $\mathrm{L}$ & 33 & 39 & 76 & \\
\hline \multicolumn{5}{|l|}{ Histology } \\
\hline Differentiated & 59 & 61 & 142 & \multirow[t]{2}{*}{ NS } \\
\hline Undifferentiated & 39 & 45 & 94 & \\
\hline \multicolumn{5}{|l|}{ Depth } \\
\hline m-sm & 47 & 48 & 112 & \multirow[t]{2}{*}{ NS } \\
\hline $\mathrm{mp}-$ & 51 & 58 & 124 & \\
\hline \multicolumn{5}{|l|}{$\mathrm{n}$} \\
\hline- & 56 & 68 & 132 & \multirow[t]{2}{*}{ NS } \\
\hline+ & 38 & 35 & 92 & \\
\hline \multicolumn{5}{|l|}{$\mathrm{H}$} \\
\hline- & 6 & 5 & 10 & \multirow[t]{2}{*}{ NS } \\
\hline+ & 92 & 101 & 226 & \\
\hline \multicolumn{5}{|l|}{$\mathrm{P}$} \\
\hline- & 7 & 9 & 17 & \multirow[t]{2}{*}{ NS } \\
\hline+ & 91 & 97 & 219 & \\
\hline \multicolumn{5}{|l|}{$M$} \\
\hline- & 1 & 4 & 8 & \multirow[t]{2}{*}{ NS } \\
\hline+ & 97 & 102 & 228 & \\
\hline \multicolumn{5}{|l|}{ Stage } \\
\hline I & 53 & 69 & 122 & \multirow[t]{4}{*}{ NS } \\
\hline II & 11 & 16 & 23 & \\
\hline III & 17 & 10 & 53 & \\
\hline IV & 14 & 17 & 31 & \\
\hline
\end{tabular}

NS, no significant difference between the gastric-cancer group and the other-cancers group

Table 3. Results of logistic regression analysis

\begin{tabular}{ll}
\hline Factors & $P$ \\
\hline Sex & 0.9 \\
Past history of cancer & 0.76 \\
Histology & 0.19 \\
Depth & 0.61 \\
n & 0.54 \\
H & 0.94 \\
P & 0.89 \\
M & 0.56
\end{tabular}

5. Nagase H, Ogino K, Yoshida I, Matsuda H, Yoshida M, Nakamura H, et al. Family history-related risk of gastric cancer in Japan: a hospital-based case-control study. Jpn J Cancer Res 1996;87:1025-8.
6. Yatsuya H, Toyoshima H, Mizoue T, Kondo T, Tamakoshi K, Hori Y, et al. Family history and the risk of stomach cancer death in Japan: differences by age and gender. Int J Cancer 2002:97:688-94.

7. Kondo T, Toyoshima H, Tsuzuki Y, Hori Y, Yatsuya H, Tamakoshi K, et al. Aggregation of stomach cancer history in parents and offspring in comparison with other sites. Int J Epidemiol 2003; 32:579-83.

8. Niv Y. Family history of gastric cancer: should we test and treat for Helicobacter pylori? J Clin Gastroenterol 2003;36: 204-8.

9. Japanese Research Society for Gastric Cancer. Japanese classification of gastric carcinoma, 2nd English edition. Gastric Cancer 1998;1:10-24.

10. Inoue M, Tajima K, Yamamura Y, Hamajima N, Hirose K, Kodera Y, et al. Family history and subsite of gastric cancer: data from a case-referent study in Japan. Int J Cancer 1998;76: $801-5$. 